\title{
ANALISIS SUMBER PENDAPATAN BURUH TANI SAWIT DI DESA PASAR SELUMA KABUPATEN SELUMA
}

\section{AN ANALYSIS OF INCOME SOURCES OF PALM OIL FARM WORKER IN PASAR SELUMA VILLAGE OF SELUMA DISTRICT}

\author{
Herri Fariadi ${ }^{1)}$, Evi Andriani ${ }^{1)}$ \\ ${ }^{1)}$ Prodi Agribisnis, Fakultas Pertanian, Unived, Bengkulu \\ Email : andriani071085@gmail.com
}

\begin{abstract}
ABSTRAK
Penelitian ini bertujuan untuk : (1) mengetahui sumber pendapatan buruh tani pemanen sawit, (2). mengetahui seberapa besar tingkat produktivitas buruh tani pemanen sawit. Jenis penelitian ini adalah kuantitatif. Populasi dan sampel dalam penelitian ini adalah buruh tani pemanen sawit di Desa Pasar Seluma Kecamatan Seluma Selatan Kabupaten Seluma Provinsi Bengkulu yaitu sebanyak 43 petani. Penentuan sampel ditentukan dengan metode sensus yaitu dengan melakukan pendataan seluruh anggota populasi di lokasi penelitian. Hasil penelitian menunjukkan bahwa sumber pendapatan buruh tani pemanen sawit rakyat terdiri dari sektor pertanian yang dibagi menjadi sektor pertanian on farm (sawah) dan sektor pertanian off farm (buruh tani pemanen sawit rakyat, buruh tani padi, buruh tani cabe). Kemudian luar sektor pertanian non farm (Sopir, warung dan memancing ikan). Produktivitas buruh tani pemanen sawit rakyat yang paling banyak adalah kelas antara 382,6 - 523,9 yaitu dengan kategori rendah dengan jumlah 25 orang atau 58,14\%. Sedangkan produktivitas buruh tani pemanen sawit rakyat dengan kategori tinggi, berjumlah 4 orang responden atau 9,63\%. Rata-rata partisipasi responden adalah521,9 dengan kategori rendah.
\end{abstract}

Kata kunci: produktivitas, buruh tani pemanen sawit rakyat, sumber pendapatan

\section{ABSTRACT}

This study aims to: (1) find out the sources of income of palm harvesters, (2). find out the level of productivity of palm harvesters. This type of research is quantitative research. The population and sample in this study were palm harvesting farm laborers in Pasar Seluma Village, South Seluma District, Seluma District, Bengkulu Province, as many as 43 farmers. The sample is determined by the census method, namely by collecting data on all members of the population at the research location. The results of the study show that the sources of income of smallholder palm harvesting laborers consist of the agricultural sector which is divided into the agricultural sector on farm (paddy fields) and the off farm agricultural sector (smallholder palm harvesters, rice farm workers, chilli farm workers). Then outside the nonfarm agricultural sector consists of drivers, shop vendors and fish anglers). The productivity of the most oil palm harvesting laborers is the class between 382.6 - 523.9, which is in the low category with a total of 25 people or $58.14 \%$, while the productivity of oil palm harvesters is high, with 4 respondents or $9.63 \%$. The average participation of respondents was 52.99 with a low category. 


\section{PENDAHULUAN}

Kelapa sawit merupakan tanaman komoditas perkebunan yang cukup penting di Indonesia karena masih memiliki prospek pengembangan yang cukup cerah. Prospek pasar dari olahan kelapa sawit cukup menjanjikan, karena permintaan dari tahun ketahun mengalami peningkatan yang cukup besar, karena itu sebagai negara tropis yang masih memiliki lahan cukup luas, Indonesia berpeluang besar untuk mengembangkan perkebunan kelapa sawit, baik melalui penanaman modal asing maupun skala perkebunan rakyat (Ely, 2007).

Tanaman kelapa sawit merupakan tanaman perkebunan terluas di Provinsi Bengkulu. Berdasarkan data BPS Provinsi Bengkulu (2016), tercatat bahwa pada tahun 2016 luas lahan perkebunan kelapa sawit di Provinsi Bengkulu mencapai 206,6 ribu hektar atau $66,95 \%$ dari luas tanaman perkebunan rakyat (Hidayat, 2007). Salah satu daerah di Kabupaten seluma yang masyarakatnya membudidayakan komoditi kelapa sawit adalah Desa Pasar Seluma. Di Desa Pasar Seluma rata-rata kepemilikan lahan adalah seluas 1,16 Ha dengan kisaran kepemilikan lahan antara 0,5 ha sampai 3 ha (Profil Desa, 2017).
Peningkatan ataupun penurunan produksi dan produktivitas suatu usahatani dipengaruhi oleh peningkatan dan penurunan produksi dan produktivitas tenaga kerja yang tercakup didalamnya.Tenaga kerja pada usahausaha perkebunan seperti perkebunan kelapa sawit umumnya adalah buruh tani. Salah satu cara untuk meningkatkankan produksi kelapa sawit adalah dengan peningkatan kualitas sumber daya manusia yaitu dengan menciptakan SDM yang memiliki kemampuan memadai dan menguasai bidang kerjanya. Peningkatan produktivitas merupakan dambaan setiap perusahaan, produktivitas mengandung pengertian berkenaan dengan konsep ekonomis, filosofis, produktivitas berkenaan dengan usaha atau kegiatan manusia untuk menghasilkan barang atau jasa yang berguna untuk pemenuhan kebutuhan hidup manusia dan masyarakat pada umumnya (Husein, 2002).

Dalam melakukan usahatani kelapa sawit, faktor produksi merupakan masalah yang sering dihadapi oleh sebagian besar petani. Salah satu faktor produksi pada usahatani kelapa sawit adalah tenaga kerja atau buruh tani pada saat panen (Sukino, 2004 ; Pahan (2006); Kuncoro (2002).Dengan menggunakan buruh tani yang terampil dalam kegiatan 
pemanenan kelapa sawit berpengaruh.Untuk itu perlu dilakukan kajian produktivitas tenaga kerja pemanen kelapa sawit.

\section{METODE PENELITIAN}

\section{Pemilihan Lokasi Penelitian}

Lokasi Penelitian dilakukan di Desa Pasar Seluma Kecamatan Seluma Selatan Kabupaten Seluma Provinsi Bengkulu. Dipilihnya desa ini sebagai tempat penelitian karena di Desa Pasar Seluma Kecamatan Seluma Selatan Kabupaten Seluma Provinsi Bengkulumerupakan desa yang mayoritas penduduknya adalah berusahatani kelapa sawit.

Teknik Penentuan Sasaran dan Informasi Penelitian

Populasi dalam penelitian ini adalah buruh tani pemanen sawitdi Desa Pasar Seluma Kecamatan Seluma Selatan Kabupaten Seluma Provinsi Bengkulu.sebanyak 43 orang. Sehingga semua buruh tani pemanen sawitdi Desa Pasar Seluma Kecamatan Seluma Selatan Kabupaten Seluma Provinsi Bengkuluadalah menjadi sampel yaitu sebanyak 43 orang.

\section{Teknik Pengumpulan Data}

Data primer diperoleh dari hasil wawancara langsung dengan para buruh tani pemanen sawit yang dijadikan responden dengan menggunakan daftar pertanyaan (kuesioner).Data sekunder diperoleh dari kantor-kantor dan instansi yang erat kaitannya dengan penelitian ini.Teknik pengumpulan data yang digunakan adalah observasi lapangan, kuisioner dan dokumentasi.

\section{Analisis Data}

Untuk mengetahui produktivitas buruh tani pemanen sawit, analisis data yang digunakan adalah :

$$
\mathbf{N P}=\frac{\mathbf{Y}}{\mathbf{L}}
$$

Keterangan : NP $=$ Nilai produktivitas kerja (kg/jam), Y = Jumlah hasil sadapan (Kg), L = Jumlah jam kerja (jam)

Setelah nilai produktivitas kerja diperoleh, kemudian dianalisis tingkat produktivitas dengan menentukan kriteria produktivitas kerja buruh tani pemanen sawit dengan menggunakan rumus interval sebagai berikut (Noer, 2004) :

Interval $=\frac{\mathrm{Pt}_{\mathrm{t}} \mathrm{Pr}_{\mathrm{r}}}{\mathrm{a}}$

Keterangan: $\mathrm{Pt}=$ Produktivitas tertinggi, $\operatorname{Pr}=$ Produktivitas terendah

Untuk mengetahui struktur pendapatan rumah tangga buruh tani pemanen sawit, yaitu dengan menganalisis pendapatan sebagai buruh tani pemanen 
sawit dan pendapatan yang berasal dari luar kegiatan buruh tani pemanen sawit serta pendapatan masing-masing anggota keluarga rumah tangga buruh buruh tani pemanen sawit, dengan melakukan interview pada waktu mengisi kuisioner langsung kepada responden. Pendapatan tersebut dianalisis menggunakan rumus sebagai berikut (Soekartawi (2002) Pd = TR TC

TR $=$ Y. Py

Keterangan :

$\mathrm{Pd}=$ Pendapatan $(\mathrm{Rp} /$ Bulan $), \mathrm{TR}=$ Total penerimaan (Rp/Bulan)

$\mathrm{TC}=$ Biaya dalam proses penyadapan (Rp/Bulan)

$\mathrm{Y}=$ Jumah hasil panen (Kg/Bulan)

Py = Harga Kelapa Sawit $(\mathrm{Rp} / \mathrm{Kg})$

Pendapatan yang diperoleh dari masing-masing anggota rumah tangga tersebut akan menjadi sumbangan pendapatan terhadap pendapatan rumah tangga (Rachman dan Supriyati, 2002).

Pendapatan rumah tangga dirumuskan sebagai berikut $: \mathbf{P t}=\mathbf{P n}+\mathbf{P w}+\mathbf{P c}$

Keterangan $: \mathrm{Pt}=$ Pendapatan keluarga $(\mathrm{Rp}), \mathrm{Pn}=$ Pendapatan Suami $(\mathrm{Rp}), \mathrm{Pw}=$ Pendapatan istri $(\mathrm{Rp}), \mathrm{Pc}=$ Pendapatan anggota keluarga yang lain seperti anak

\section{HASIL DAN PEMBAHASAN}

\section{Tingkat Produktivitas Buruh Tani Pemanen Sawit}

Nilai produktivitas buruh tani pemanen sawit dihitung dengan membagikan rata-rata hasil panen dengan jumlah jam kerja. Hasi panen merupakan banyaknya buah kelapa sawit yang mampu diperoleh oleh seorang pemanen sawit $(\mathrm{Kg} / \mathrm{B} \ln )$.

Berdasarkan hasil penelitian, produktivitas kerja buruh tani pemanen sawit dengan rata-rata 521,9. Produktivitas kerja merupakan ukuran hasil kerja yang dilakukan. Semakin besar produktivitas kerja seseorang maka semakin besar hasil kerja yang diperoleh (Husen, 2002). Produktivitas kerja buruh tani pemanen sawit rakyat memiliki kategori rendah yaitu dengan rata-rata 521,9 (Tabel 2). Rendahnya tingkat produktivitas buruh tani pemanen sawit rakyat di Desa Pasar Seluma Kecamatan Seluma Selatan Kabupaten Seluma Provinsi Bengkulu, berdasarkan informasi dari responden disebabkan karena tingginya ukuran tanaman sawit yang dipanen, sehingga menyebabkan banyaknya waktu yang terpakai untuk proses pemanenan tersebut. Kemudian berdasarkan ketua adat setempat, bahwa 
dalam proses pemanen di perlukan ketelitian karena kelapa sawit memiliki duri dan buah yang keras dan besar sehingga dapat memakan waktu yang lama dalam proses panen tersebut (Almigo, 2014).

\section{Tabel 1. Produktivitas Buruh Tani Pemanen Kelapa Sawit}

\begin{tabular}{lll}
\hline No & Uraian & $\begin{array}{l}\text { Produktivitas buruh tani pemanen } \\
\text { kelapa sawit }(\mathrm{Kg} / \mathrm{Jam} / \mathrm{Th})\end{array}$ \\
\hline 1. & Jumlah Panen & $493.279,76$ \\
2. & Jumlah Jam & 735,07 \\
& Produktivitas & $\mathbf{5 2 1 , 9}$ \\
\hline
\end{tabular}

Sumber: Data Primer

Tabel 2.Tingkat Produktivitas Buruh Tani Pemanen Kelapa Sawit

\begin{tabular}{llcc}
\hline No & \multicolumn{1}{c}{$\begin{array}{c}\text { Kategori Tingkat } \\
\text { Produktivitas (skor) }\end{array}$} & Rata-rata & Tingkat Produktivitas \\
& \multicolumn{1}{c}{ Rendah $=382,6-523,9$} & 521,9 & Rendah \\
2 & Sedang $=524-665,2$ & & $382,6-523,9$ \\
3 & Tinggi $=665,3-$ & & \\
& 806,5 & & \\
\hline
\end{tabular}

Sumber: Data Primer

Produktivitas buruh tani pemanen sawit rakyatdi Desa Pasar Seluma Kecamatan Seluma Selatan Kabupaten Seluma Provinsi Bengkulu yang paling banyak adalah kelas antara 382,6 - 523,9 yaitu dengan kategori rendah dengan jumlah 25 orang atau $58,14 \%$. Sedangkan produktivitas buruh tani pemanen sawit rakyatdengan kategori tinggi, berjumlah 4 orang responden atau $9,63 \%$.
Semakin besar produktivitas kerja seseorang maka semakin besar hasil kerja yang diperoleh (Gambar 1). Secara filosofis produktivitas mengandung pengertian pandangan hidup dan sikap mental yang selalu berusaha untuk meningkatkan mutu kehidupan, keadaan hari ini harus lebih baik dari hari kemarin dan mutu kehidupan harus lebih baik dari hari ini. Dalam penelitian ini produktivitas pemanen sawit diartikan sebagai hasil 
yang diperoleh dari kegiatan memanen sawit dan telah dikurangi dengan jumlah basis usaha tersebut. Hasil penelitian menunjukkan bahwa persentase produktivitas tertinggi berada pada kategori rendah. Untuk itu perlu di cari alternatif untuk meningkatkan produktivitas buruh tani pemanen sawit rakyat, meskipun karena tingginya ukuran tanaman sawit yang dipanen atau karena kelapa sawit memiliki duri dan buah yang keras dan besar sehingga dapat memakan waktu yang lama dalam proses panen tersebut. Semakin besar produktivitas kerja seseorang maka semakin besar hasil kerja yang diperoleh (Gambar 1). Secara filosofis produktivitas mengandung pengertian pandangan hidup dan sikap mental yang selalu berusaha untuk meningkatkan mutu kehidupan, keadaan hari ini harus lebih baik dari hari kemarin dan mutu kehidupan harus lebih baik dari hari ini. Dalam penelitian ini produktivitas pemanen sawit diartikan sebagai hasil yang diperoleh dari kegiatan memanen sawit dan telah dikurangi dengan jumlah basis usaha tersebut. Hasil penelitian menunjukkan bahwa persentase produktivitas tertinggi berada pada kategori rendah. Untuk itu perlu di cari alternatif untuk meningkatkan produktivitas buruh tani pemanen sawit rakyat, meskipun karena tingginya ukuran tanaman sawit yang dipanen atau karena kelapa sawit memiliki duri dan buah yang keras dan besar sehingga dapat memakan waktu yang lama dalam proses panen tersebut.

Tabel 3. Distribusi produktivitas Buruh Panen Kelapa Sawit Rakyat di Desa Pasar Seluma

\begin{tabular}{llcc}
\hline No & $\begin{array}{c}\text { Kategori Tingkat Produktivitas } \\
(\text { skor })\end{array}$ & Jumlah (jiwa) & Persen (\%) \\
\hline 1 & Rendah $=382,6-523,9$ & 25 & 58,14 \\
2 & Sedang $=524-665,2$ & 14 & 32,56 \\
3 & Tinggi $=665,3-806,5$ & 4 & 9,36 \\
\hline Jumlah & 32 & 100 \\
\multicolumn{2}{l}{ Rata-rata : 521,9} & & \\
\hline
\end{tabular}




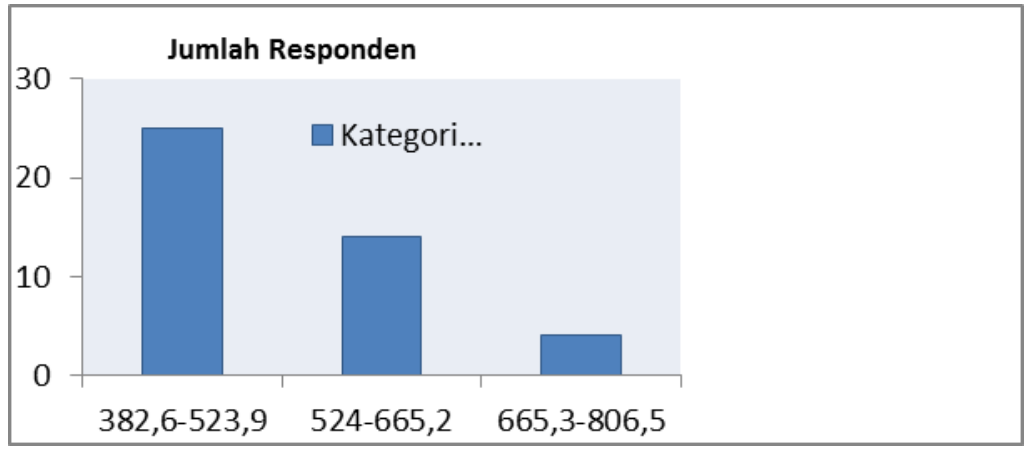

Gambar 1. Grafik Produktivitas Buruh Tani Pemanen Sawit Rakyat

Struktur Pendapatan Buruh Tani

Pemanen Sawit Rakyat

Struktur pendapatan yang dimaksud penelitian ini adalah struktur nafkah rumahtangga pemanen kelapa sawit rakyat di Desa Pasar Seluma Kecamatan Seluma Selatan Kabupaten Seluma Provinsi Bengkulu., melalui kombinasi aktivitas-aktivitas ekonomi di bidang pertanian dan non pertanian. Wilayah-wilayah sekitar Desa di Desa Pasar Seluma merupakan daerah pedesaan, dimana sebagian besar masyarakatnya masih mengandalkan sektor pertanian untuk mencukupi kebutuhan hidupnya maupun menambah pendapatan rumah tangga, dengan kata lain sektor pertanian masih merupakan basis ekonomi yang penting bagi rumah tangga pedesaan di sekitar di Desa Pasar Seluma.

Secara umum struktur pendapatan dibagi menjadi dua yaitu kelompok pendapatan disektor pertanian (on farm dan off farm) dan non pertanian. Persentase buruh tani pemanen sawit rakyat yang bekerja di luar sektor pertanian ada sektor pertanian on farm yaitu sawah yaitu sebesar 25,58\%. Pada sektor pertanian off farm masyarakat Desa Pasar seluma bekerja sebagai buruh tani. Pemanen sawit rakyat, Buruh tani padi dan buruh tani cabe. Hal ini dilakukan untuk menambah pendapatan untuk mencukupi kebutuhan sehari-hari. Persentase masyarakat Desa Pasar Seluma yang bekerja sebagai buruh tani padi yaitu sebesar 9,30\%. Kemudian buruh tani pemanen sawit rakyat yang tanpa memiliki usaha sampingan adalah sebanyak 14 orang dengan persentase sebesar $32,56 \%$. Diluar sektor pertanian struktur pendapatan buuh tani pemanen sawit rakyat adalah sopir, warung dan memancing ikan untuk dijual. Persentase terbesar adalah pada pekerjaan memancing ikan yaitu sebesar 9,30\%. 
Selanjutnya sopir sebesar $6,98 \%$ dan warung sebesar 4,65\% (Tabel 4).

Dari hasil penelitian dapat dilihat bahwa struktur pendapatan buruh tani pemanen sawit rakyat dari sektor dan dari luar sektor pertanian. Hal ini membuktikan bahwa pendapatan rumah tangga buruh tani pemanen sawit rakyat didalam penelitian berasal dari sumber pendapatan ganda yaitu dari sektor pertanian dan luar sektor pertanian. Hal ini sesuai dengan pernyataan Wayan dan Suryadi (2004) pada masyarakat pedesaan strategi pola nafkah ganda merupakan strategi nafkah yang paling banyak dilakukan oleh rumahtangga pedesaan.Nafkah ganda atau beragam sumber pendapatan berarti sebuah kombinasi dari banyak pekerjaan yang dimiliki oleh seseorang, yang terdiri dari aktivitas-aktivitas ekonomi pokok di bidang pertanian dan non pertanian. Aktivitas non pertanian merupakan sampingan di luar pekerjaan pokok dari sebuah bentuk rumahtangga pedesaan dan mungkin pekerjaan dilakukan oleh kepala rumahtangga atau anggota dari sebuah rumahtangga, dan aktivitas tersebut mungkin secara langsung atau tidak langsung tapi secara positif menciptakan pendapatan yang esensial untuk menjamin keberadaan rumahtangga (Iskandar, 2002).

Struktur pendapatan buruh tani pemanen sawit rakyat di Desa Pasar Seluma pada sektor pertanian On Farm, sawah adalah sumber nafkah buruh tani pemanen sawit rakyat dengan ratarata pendapatan sebesar $\mathrm{Rp}$ 8.509.091/Tahun. Sedangkan struktur pendapatan buruh tani pemanen sawit rakyat di Desa Pasar Seluma pada sektor pertanian Of Farmyang terbesar adalah sebagai buruh tani pemanen sawit rakyat yaitu sebesar Rp 14.626.318/Tahun (Tabel $5)$.

Tabel 4. Persentase Struktur Pendapatan Buruh Tani Pemanen Sawit Rakyat di Desa Pasar Seluma

\begin{tabular}{|c|c|c|c|}
\hline No & $\begin{array}{l}\text { Sumber Penerimaan Rumah } \\
\text { Tangga Pemanen Sawit Rakyat }\end{array}$ & $\begin{array}{l}\text { Jumlah Buruh Tani } \\
\text { Sawit Rakyat (KK) }\end{array}$ & Persen $(\%)$ \\
\hline \multirow[t]{5}{*}{1} & Dalam Sektor Pertanian & & \\
\hline & 1. Sektor On Farm & & \\
\hline & a. Sawah & 11 & 25,58 \\
\hline & 2. Sektor Off Farm & & \\
\hline & a. Buruh Tani Sawit Rakyat (tanpa & 14 & 32,56 \\
\hline
\end{tabular}


usaha sampingan)
b. Buruh Tani Padi
4
9,30
c. Buruh Tani Cabe
5
11,63

2 Luar Sektor Pertanian Non Farm
a. Sopir
3
6,98
b. Warung
2
4,65
c. Memancing Ikan
4
9,30

Jumlah

43

100

Sumber: Data Primer

Tabel 5. Rata-rata Pendapatan Rumah Tangga Buruh Tani Pemanen Sawit Rakyat Berdasarkan Struktur Pendapatan

\begin{tabular}{lccc}
\hline No & $\begin{array}{c}\text { Sumber Penerimaan Rumah Tangga Pemanen } \\
\text { Sawit Rakyat }\end{array}$ & X & \\
\hline 1 & Dalam Sektor Pertanian
\end{tabular}

$1 \quad$ Dalam Sektor Pertanian

1. Sektor On Farm
a. Sawah
$11 \quad 8.509 .091$

2. Sektor Off Farm

\begin{tabular}{llr} 
a. Buruh Tani Sawit Rakyat (tanpa usaha & 14 & 14626318 \\
sampingan) & 4 & 10.800 .000 \\
b. Buruh Tani Padi & 5 & 2.070 .000 \\
$\begin{array}{l}\text { c. Buruh Tani Cabe } \\
\text { Luar Sektor Pertanian Non Farm }\end{array}$ & 3 & 11.600 .000 \\
$\begin{array}{l}\text { a. Sopir } \\
\text { b. Warung } \\
\text { c.Memancing Ikan }\end{array}$ & 2 & 7.200 .000 \\
\hline
\end{tabular}

Sumber: Data Primer diolah. Keterangan : $X=$ Jumlah Buruh Tani Sawit Rakyat (KK), Y= Rata-rata Pendapatan (Rp/Tahun).

Hal ini menunjukkan bahwa buruh tani pemanen sawit rakyat masih menjadi sumber nafkah utama masyarakat Desa Pasar Seluma. Menurut Budiono (2002), tingginya pendapatan seseorang ditentukan oleh jumlah faktor produksi yang dimiliki dan harga per unit dari masing-masing faktor produksi serta biaya 
yang harus dikorbankan untuk kegiatan usaha tersebut. Jenis pendapatan sampingan yang menjadi sumber penerimaan terbesar adalah sopir yaitu rata-rata pendapatan sebesar Rp.11.600.000 per tahun. Hal ini memperlihatkan bahwa buruh tani pemanen sawit rakyat di Desa Pasar Seluma ada yang bekerja sebagai Sopir pasir yang dilakukan apabila tidak bekerja sebagai buruh tani pemanen sawit rakyat, mereka bekerja untuk menambah pendapatan keluarga sehingga memiliki dua sumber pendapatan, tidak hanya mengandalkan buruh tani pemanen sawi rakyat saja. Selain ituada yang bekerja dengan membuka warung dengan rata-rata pendapatan sebesar Rp 7.200.000 per tahun.

\section{Tabel 6. Jenis Pendapatan Sampingan Buruh Tani Pemanen Sawit Rakyat}

$\begin{array}{ccc}\text { Jenis pendapatan } & \text { Jumlah Buruh Tani } & \text { Rata-rata Pendapatan } \\ \text { Sampingan Petani } & \text { Sawit Rakyat (KK) } & \text { (Rp/Tahun). }\end{array}$

1. Sawah

2. Buruh Tani Padi

3. Buruh Tani Cabe

4. Sopir

5. Warung

6. Memancing Ikan

11
4 5 3 2 4

8.509 .091

10.800 .000

2.070 .000

11.600 .000

7.200 .000

6.920 .000

Sumber: Data Primer

Kemudian bekerja memancing ikan dengan rata-rata pendapatan adalah sebesar Rp6.920.000 per tahun. Sumber pendapatan terkecil adalah buruh tani cabe dengan rata-rata pendapatan adalah sebesar Rp 2.070.000 pertahun (Tabel 6).

\section{KESIMPULAN}

Produktivitas buruh tani pemanen sawit rakyat di Desa Pasar Seluma Kecamatan Seluma Selatan Kabupaten Seluma Provinsi Bengkulu yang paling banyak adalah kelas antara 382,6 - 523,9 yaitu dengan kategori rendah dengan jumlah 25 orang atau $58,14 \%$. Sedangkan produktivitas buruh tani pemanen sawit rakyat dengan kategori tinggi, berjumlah 4 orang responden atau 9,63\%. Rata-rata partisipasi responden adalah 521,9 dengan kategori rendah.

Struktur pendapatan buruh tani pemanen sawit rakyat di DesaPasar Seluma Kecamatan Seluma Selatan Kabupaten Seluma Provinsi Bengkulu 
terdiri atas dalam sektor pertanian yang dibagi menjadi sektor pertanian on farm (sawah) dan sektor pertanian off farm (buruh tani pemanen sawit rakyat, buruh tani padi, buruh tani cabe).Kemudian luar sektor pertanian non farm (Sopir, warung dan memancing ikan).

\section{UCAPAN TERIMA KASIH}

Penelitian merupakan Hibah

Penelitian Desentralisasi dengan Skema Penelitian Dosen pemula (PDP) yang di biayai Oleh Direktorat Jenderal Penguatan Riset dan Pengembangan (DRPM) Kementerian Riset, Teknologi dan Pendidikan Tinggi Nomor SP DIPA042.06.1.401516/2017.

\section{DAFTAR PUSTAKA}

Almigo, N. 2014. Hubungan Antara Kepuasaan Kerja Dengan Produktivitas Kerja Karyawan. Jurnal Kepuasan Kerja, Imbala, Masa Kerja dan Produktivitas Kerja Karyawan I (1) : 50-60

Ely. 2007. Kelapa Sawit. Penebar Swadaya. Jakarta.
Hidayat, A. 2007.Peta Kesuaian Lahan dan Peta Arahan Tata Ruang Pertanian.Warta Sumberdaya Lahan.Vol. 3 No. 3 Desember 2007.

Husein.2002. Sumber Daya Manusia dan Produktivitas Kerja. CV. Mandar Maju. Bandung.

Iskandar. 2002. Etos Kerja, Motivasi dan Sikap Inovatif Terhadap Produktivitas Petani. Jurnal Makara. Sosial Humaniora. 6 (1) : 26-29. Universitas Negeri Jakarta. Jakarta.

Kuncoro.2002. Upah Sistem Bagi Hasil dan Penyerapan Tenaga Kerja. Jurnal Ekonomi Pembangunan Kajian Ekonomi Negara Berkembang 7 (1) : 45:56. Mahasiswa Program Doktor Ilmu Ekonomi. Program Pascasarjana UGM. Yogyakarta.

Pahan, Iyung, 2006. Panduan Lengkap Kelapa Sawit. Manajemen Agribisnis dari Hulu hingga Hilir. Penebar Swadaya, Jakarta.

Profil Desa Pasar Seluma. 2015. Profil Desa Pasar Seluma. Provinsi Bengkulu.

Soekartawi, 2006.Teori Ekonomi Produksi. Rajawali Pers. Jakarta.

Sukino.2004. Manajemen Sumberdaya Manusia dan Potensi Unggulan Daerah. Bumi Aksara. Jakarta.

Wayan dan Suryadi.2004. Ekonomi Tenaga Kerja Pertanian dan Imlikasinya dalam Peningkatan Produksi dan Kesejahteraan Buruh Tani. Jurnal Litbang Pertanian. 23 (3):91-99.

Bogor. 